\title{
Lexicografia cultural do Semiárido baiano ${ }^{1}$
}

\author{
Lexicography cultural of the Semiárido baiano
}

\author{
Cosme Batista dos Santos \\ Universidade do Estado da Babia \\ Juazeiro, Bahia, Brasil
}

\begin{abstract}
Resumo: Este trabalho tem como objetivo apresentar resultados parciais da pesquisa sobre a lexicografia cultural do semiárido baiano. A pesquisa foi financiada pela Fundação de Amparo à Pesquisa do Estado da Bahia (FAPESB) e pela Universidade do Estado da Bahia (UNEB). O pressuposto central da pesquisa é a lexicografia cultural, atualizada a partir de pressupostos metodológicos da linguística aplicada, da etnolexicografia (PEREZ, 2000) e da pragmática lexicultural (GALISSON, 2001). Os estudos foram realizados em contextos de formação de educadores, a partir da pesquisa-formação (MARIANO, 2013), tendo como instrumentos a oficina de lexicografia cultural e a edição lexicográfica de palavras culturalmente relevante nas comunidades rurais e urbanas do sertão semiárido baiano. Durante a realização de oficinas, constatamos as dificuldades de trazer a dimensão pragmática das palavras para a edição de verbetes lexicográficos, por isso a proposta de trabalho é motivada por essa necessidade de conhecer os fundamentos da lexicografia (PONTES, 2001) e da lexicografia sociocultural (ISQUERDO, 1998). Em fichas lexicográficas, foram levantadas as palavras em corpus de língua falada, textos literários e documentários. No final de cada oficina, os professores em formação editaram os seguintes dicionários: o Dicionário regional do Uauá, organizado por uma educadora, em parceria com estudantes de Ensino Médio; o $A B C$ do vaqueiro, organizado por um grupo de educadores da Plataforma Freire; e o $A B C$ do artesanato Kiriri, por um grupo de Educadores da Licenciatura Intercultural de Educação Escolar Indígena.
\end{abstract}

Palavras-chave: Formação de educadores. Lexicografia cultural. Semiárido. Pesquisa-formação.

\begin{abstract}
This paper aims to present results of a survey on cultural lexicography in the formation of the Bahian semi-arid teachers. The research was funded by the Foundation for the Bahia State Research (FAPESB) and the University of the State of Bahia (UNEB). The central premise of the research is lexicography in its intercultural face, updated from methodological assumptions of applied linguistics. The studies were conducted in teacher training contexts, from the research-training (MARIANO, 2013), with the instruments of cultural workshop lexicography and lexicographical editing culturally relevant words in rural and urban communities of the Bahia semi-arid hinterland. During the workshops, we see the difficulties of bringing the pragmatic dimension of words for editing lexicographical entries, so the proposed work is motivated by the need to know the basics of lexicography (PONTES, 2001), social lexicography (ISQUERDO, 1998), and lexicographical chips. The words were raised in spoken language corpus, literary texts and documentaries. At the end of each workshop student teachers edited the following dictionaries: the Regional dictionary of Uauá, organized by a teacher, in partnership with high school students; the $A B C$ comboy, organized by a group of educators Freire Platform; and the $A B C$ Kiriri's crafts, by a group of educators Intercultural of Indigenous Education.
\end{abstract}

Keywords: Teacher training. Cultural lexicography. Semiarid. Research-training.

\footnotetext{
${ }^{1}$ Uma primeira versão deste estudo foi publicada inicialmente no livro As palavras e as culturas, organizado por mim e por Rita Queiroz, em 2017, editado pela Editora da Universidade do Estado da Bahia EDUNEB.

*Professor do Programa de Pós-Graduação em Crítica Cultural - POSCRÍTICA - Universidade do Estado da Babia, Juazeiro, Bahia, Brasil. E-mail: cosmebs.santos@gmail.com.
} 


\section{INTRODUÇÃO}

A pesquisa na área de humanidades, especialmente a que atenta para as produções cultural e sociolinguística do semiárido, ainda é pouca e despercebida. Essa lacuna cria um espaço em branco, um território sem estudos que torna o vasto sertão e os sertanejos estranhos ao Brasil das capitais e dos grandes centros urbanos. Em função dessa lacuna, não é raro encontrarmos, principalmente em livros didáticos e em discursos midiáticos, significados distorcidos do povo e dos costumes do semiárido brasileiro. Normalmente, esses suportes tendem a reduzir essa realidade a uma foto de mato seco ou de chão rachado e, quase sempre, ignoram o povo sertanejo como produtor de cultura e de conhecimentos. Incomodou-nos muito no início da elaboração deste estudo, por exemplo, a ausência de uma lexicografia que acolhesse dedicadamente certas palavras tão relevantes para a cultura sertaneja na Bahia, como o é, por exemplo, a palavra Umbuzada, a nossa mais apreciada batida de umbu com leite, e a quase total ausência de significados culturalmente partilhados sobre diversos lexemas que são dicionarizados como regionalismos, brasileirismos, tornando invisível a dimensão pragmática.

Dessa forma, este artigo tem como objetivo mais amplo apresentar uma parte dos resultados do projeto Estudos Lexicográficos do Sertão Semiárido, que foi financiado pela Fundação de Amparo à Pesquisa do Estado da Bahia - FAPESB, através do edital Articulação em Rede para o Semiárido, e buscar integrar pressupostos ou uma combinação de pressupostos para alimentar a ambição de desenvolver, durante a realização da pesquisa, uma linha que chamamos de lexicografia sociocultural (ISQUERDO, 1998) e, com isso, proporcionar aos estudantes o acesso à cultura através de suas palavras. Inicialmente, vale destacar, uma das linhas de pesquisa do projeto se voltou mais insistentemente para este foco, ou seja, a investigação das culturas ativas no semiárido brasileiro, tomando como referência as palavras em uso em diferentes grupos e comunidades. Na ocasião, atentamos para a inclusão de uma dimensão pragmática nos verbetes, por exemplo, buscando os elementos do contexto de uso, funções, explicações e exemplos. Esse exercício ficou mais evidente na edição do verbete Ajuntamento, a seguir, produzido para o $A B C$ do Vaqueiro: 


AJUNTAMENTO
a.jun.ta.men.to/substantivo. Arrebanhamento de ovelhas que se
encontram fora de seu pasto, para que sejam reconduzidas às fazendas
de origem. No ajuntamento, todas as ovelhas que são encontradas em
uma determinada área são recolhidas para uma fazenda, depois
separadas (a esse processo chamam de apartação) e depois retiradas
para seus locais. Embora o termo de uso mais frequente para o processo
seja ajuntamento, usa-se também apartação e às vezes retirada,
mas que fique claro que são etapas diferentes de um mesmo processo.
Para ovelhas, o normal é o uso do termo ajuntamento. Para gado,
embora o processo seja muito parecido, podemos dizer idêntico, o termo
utilizado é a retirada, porque se refere à retirada do gado desgarrado
de um pasto estranho tendo em vista o seu retorno para o pasto de seu
curral. (LOPES, 2014)

$\mathrm{O}$ verbete acima contém informações gramaticais, semânticas e pragmáticas, por exemplo, com a explicação do fenômeno Ajuntamento, na prática social do vaqueiro, no dia a dia. Nota-se o esforço do autor do verbete para verbalizar as ações que envolvem o Ajuntamento em campo, no entanto, em outros casos, as definições obedecem ao mesmo estatuto das definições denotativas tipicamente empregadas na cultura lexicográfica tradicional brasileira. Enfim, a pesquisa com o léxico da cultura do vaqueiro resultou na visibilidade de certas palavras ausentes nos dicionários da língua portuguesa brasileira, sem dar conta da carga cultural implícita nas palavras.

O texto está organizado da seguinte forma: inicialmente, traz o pressuposto central da pesquisa, isto é, a lexicografia intercultural, desenvolvida na linguística aplicada como uma orientação para a pesquisa na e com a formação do professor em seu local de trabalho. A pesquisa, portanto, é um desdobramento de pesquisa-formação ou de uma pesquisa-ação orientada para a formação continuada de educadores (MARIANO, 2013). Particularmente, para essa experiência, foi realizada a oficina de lexicografia cultural, tendo em vista a edição lexicográfica de palavras culturalmente relevantes nas comunidades rurais e urbanas do sertão semiárido baiano, incluindo a cultura catingueira. Durante a realização de oficinas, constatamos as dificuldades dos educadores de trazer a dimensão pragmática das palavras para a edição de verbetes lexicográficos, por isso a proposta de trabalho é motivada por essa necessidade de conhecer os fundamentos da lexicografia (PONTES, 2001) e da lexicografia sociocultural (ISQUERDO, 1998). Em fichas de registros lexicográficos, foram levantadas as palavras em corpus de língua falada, textos literários e documentários e, no final de cada oficina, os professores em formação editaram os seguintes dicionários: o Dicionário regional do Uauá, organizado por uma educadora, em parceria com estudantes de Ensino Médio; o $A B C$ do vaqueiro, organizado por um grupo de educadores da Plataforma Freire; e o $A B C$ do artesanato Kiriri, por um grupo de Educadores da Licenciatura Intercultural de Educação Escolar Indígena. 


\section{PRESSUPOSTOS TEÓRICOS: DA ABORDAGEM SÓCIO-HISTÓRICA À ABORDAGEM CULTURAL DA LEXICOGRAFIA}

Apresentamos aqui os pressupostos teóricos que embasam esta pesquisa: da abordagem sócio-histórica à abordagem cultural da lexicografia.

\subsection{A ABORDAGEM SÓCIO-HISTÓRICA}

Os estudos sobre o léxico, numa vertente sócio-histórica, valorizam a relação entre as diferentes lexias, os povos e as comunidades em que elas se manifestam. A rigor não é apenas o conhecimento da estrutura linguística da palavra que interessa, mas, fundamentalmente, o que as pessoas manifestam e como se manifestam através dela.

Qual é a identidade cultural que o léxico revela e qual é identidade lexical que nos faz conhecer certo grupo ou região de usuários da língua? Em outros termos, o léxico de uma língua não pode ser reduzido a uma lista de palavras. As palavras revelam a identidade cognitiva, sociolinguística e cultural dos seus utilizadores, grupo social que as usa, e das condições sociais e históricas em que são usadas (ISQUERDO, 1998; MARCUSCHI, 2004; QUEIROZ, 2014).

A trajetória lexical é reveladora do percurso histórico seguido pelos agrupamentos comunitários, marca as relações de identidade, ao mesmo tempo em que nomeia o meio circundante. A construção de palavras, mais que uma escolha simples, insinua a relação com o contexto social e a recepção de mudanças, quase sempre chegadas por intermédio das transformações tecnológicas. Além disso, o léxico pode indicar ritos, celebrações, relações laborais ou, por outro lado, silêncios, interdições, tabus. Na prática de edição lexicográfica, em especial nas suas tentativas de definir a língua nacional, regional ou baiana, há, da mesma forma, sérios riscos de invisibilidade cultural. Isso também ocorre na produção de estereótipos, quando se tenta desvincular o corpus linguístico das práticas culturais específicas ou das motivações sócio-históricas das significações lexicográficas.

A investigação aqui pretendida, portanto, pretende dar igual valor a esses elementos, sendo que o risco de deixar os usos em segundo plano é sempre uma possibilidade real. Efetivamente, o abandono dos desenhos relacionados à lexicografia regional não acontece por mero esquecimento de sua existência conceitual, mas por uma opção de iniciar a formulação de caminhos para a pesquisa da relação entre o léxico e a cultura considerando que o léxico é um modo privilegiado de acesso à cultura. $\mathrm{E}$ a lexicografia que se funda nessa orientação não poderá ser outra senão o campo de estudos que incorpora, interdisciplinarmente, estudos culturais, históricos, sociolinguísticos, etnográficos, discursivos, enfim pragmáticos. A lexicografia não se reduz a um problema semântico, embora o acolha, mas o sentido que interessa à lexicografia intercultural não deriva apenas da interpretação das palavras pelos linguistas ou pelos lexicógrafos. O sentido é interculturalmente situado e, por isso, o que interessa para esta pesquisa é o sentido manifestado em corpus, tal como pressupõem muitos estudos linguísticos na lexicologia e na lexicografia. Porém, mais amplamente, a proposta desse trabalho é difundir o sentido da palavra que está em uso e que, fundamentalmente, está implicada nas práticas culturais 
que definem uma comunidade linguística e um território de identidade. Em termos mais claros, nas nossas propostas de trabalho, o usuário é parte e, por isso, não corremos o risco de resgatar o sentido das palavras fazendo desaparecer o seu usuário ou grupos de usuários.

Alguns estudos, seguindo a orientação sócio-histórica, têm se dedicado mais amplamente a pesquisas sobre a lexicografia regional, por exemplo, mapeando, através de corpus, o léxico dos lugares e estudando a influência cultural e geográfica na configuração da identidade lexical de regiões e estados brasileiros (ISQUERDO, 1998; CARDOSO, 2012).

Aparecida Neri Isquerdo realizou uma pesquisa vasta sobre o "vocabulário regional na Amazônia acreana". Trata-se de um estudo sobre o vocabulário do seringueiro do Estado do Acre que objetivou inventariar, descrever e analisar aspectos do léxico utilizado pelo grupo, com vistas a verificar em que medida esse nível da língua pode retratar a realidade física, social e cultural da região acreana e do grupo de seringueiros em particular. Em seu estudo, Isquerdo (1998) concluiu que

o predomínio de lexias não dicionarizadas e de emprego específico do grupo recai no campo referente à atividade da seringa (...). Por integrarem o vocabulário básico do grupo com significação já cristalizada no âmbito dos seringais, essas lexias são próprias e específicas de um subsistema regional. Dessa forma, essa parcela significativa de unidades lexicais enriquece sobremaneira o universo lexical da língua portuguesa do Brasil com regionalismos característicos de uma região notadamente marcada pelas suas peculiaridades físico-culturais, econômicas e linguísticas. (ISQUERDO, 1998, p. 103)

Outra conclusão importante relativa à lexicografia regional da Amazônia acreana é que a autora acrescenta a essa pesquisa os modos de investigação sobre a identidade lexical regional, por exemplo, quando aponta que o isolamento em termos geográficos e sociais e, inclusive, as dificuldades de acesso aos meios de comunicação de massa motivam a estabilidade lexical na língua falada, que, por sua vez, é passada de geração para geração sem significativas alterações.

No nosso estudo, embora a vertente do regionalismo pareça ser forte, uma vez que a pesquisa abrange um território específico, o semiárido baiano, optamos por um aprofundamento da investigação indo na direção das culturas e das comunidades que ocupam esse território do semiárido. A abrangência regional, portanto, não é o foco deste projeto, embora seja no interior de uma região específica que o estudo da relação entre palavras e culturas esteja sendo desenvolvido. Nesse sentido, afirmamos que as questões de identidade cultural estão pautadas em vários campos de pesquisa em nosso contexto e que o semiárido é um território de convivência entre culturas: indígena, quilombola, catingueiros, vaqueiros e outras.

O plano de trabalho aqui proposto orienta que os usos lexicais nas referidas comunidades sejam levantados através de diferentes corpora e que a investigação dedique uma forte atenção aos significados dados às palavras em cada cultura e às relações semântico-pragmáticas possíveis de se estabelecer entre as definições dadas, o que sugere para nós o revelamento da realidade intercultural mediada pela língua e pelo léxico. Em 
alguns casos, fica muito evidente uma percepção da cultura através do léxico, ou seja, é possível dizer que palavras como "gibão", "perneira" e "roló" são palavras pertencentes ao universo léxico-semântico-pragmático da cultura do vaqueiro, assim como paiosca, toré, flecha e paú são palavras pertencentes ao universo léxico-semântico-pragmático da cultura indígena no sertão semiárido. No entanto há muitos casos em que uma mesma palavra representa diferentes práticas culturais, há casos em que uma mesma palavra representa experiências culturais distintas e há casos em que diferentes palavras representam uma mesma experiência cultural para diferentes povos em diferentes sítios.

A palavra "terreiro" pode significar a "área ao redor da casa”. No entanto, na prática cotidiana, essa acepção incorpora informações pragmáticas distintas, já que, no cotidiano do povo quilombola, o terreiro, "o terreiro de candomblé", é o lugar de manifestação de culto de religião afro-brasileira, isto é, uma informação que a representação de "terreiro" na cultura indígena não comporta. Há ainda situações em que um mesmo objeto cultural recebe nomeações e funções distintas, como, por exemplo, aió e bocapiu, respectivamente, na cultura indígena e na cultura do vaqueiro. O povo Kiriri utiliza o objeto que define o "aió" como "uma sacola pequena, feita de fibra de caroá ou imbé que serve como bolsa. É utilizado na comunidade no dia a dia como utensílio de caça" (cf. REIS, 2014). Os Kiriri penduram o aió no pescoço ou no ombro, colocam estilingue e balas de estilingue e seguem pelo mato à procura de alguma caça pequena. Na cultura do vaqueiro, esse mesmo objeto "aió" é sinônimo de bocapiu e se define como "uma sacola que serve para dar milho aos cavalos" (cf. CAFÉ, 2014).

Esta complexidade, portanto, tem se tornando um constante desafio para nós, pesquisadores, em encontrar conceitos que nos permitam adentrar com mais propriedade nessas análises e organizar procedimentos de entrada nesse universo léxico-semânticopragmático. Daí que os nossos interesses pela pragmática têm se ampliando, na busca de uma abordagem em que as relações entre léxico e cultura não se definem apenas pelo demarque territorial, mas, sobretudo, por uma prática social e cultural que dão identidade às culturas e as colocam em diálogo, da mesma forma que as distanciam em alguns aspectos.

\subsection{POR UMA LEXICOGRAFIA DA CULTURA}

O aprofundamento proposto relativo à abordagem lexicultural é a parte fundamental do estudo e visa dar suporte a intervenções na formação de educadores e estudantes, tendo em vista as oficinas de intervenção pedagógica que proporcionem a educadores e estudantes entrar nas culturas do outro, através das palavras, e conhecer mais amplamente as palavras através dos usos que se fazem delas em determinados sítios culturais do sertão semiárido brasileiro e baiano. Para o desenvolvimento de programas com essa demanda, portanto, interessa definir a pragmática lexicultural como um modo de acesso às culturas através das palavras e a lexicultura como a cultura implícita nas palavras, que precisa ser revelada, explicada e interpretada (GALISSON, 1999). Esse é um pressuposto cuja importância é evidente para o ensino da língua em contextos de educação intercultural, por exemplo na educação escolar indígena e quilombola e na 
educação para a convivência com o semiárido.

A análise preliminar das palavras "chifre" e "chifrar", a seguir, mostra como essa demanda tornou-se evidente no âmbito dos estudos lexicográficos que estamos a desenvolver no semiárido do Nordeste brasileiro.

\section{Chifre}

s.m. Apêndice córneo que forma o par que guarnece a fronte de alguns animais adultos, corno, guampa.

\section{Chifrar}

v.t. agredir ou ferir com chifres.

(Minidicionário Luft. São Paulo: Ática, 2000)

As definições dicionarísticas dos lexemas "chifres" e "chifrar" são universais, lógicas, eruditas e fornecidas por quase todos os dicionários da língua portuguesa brasileira. No entanto, em uma pesquisa lexicultural, cujo foco é o léxico marcado pela carga cultural (GALISSON, 1987), o investigador deve adentrar nas práticas cotidianas de uso das palavras e trazer para o dia a dia os seus significados implícitos, evidenciá-los e interpretá-los como um meio de acesso à cultura. É evidente que nas definições acima o dicionário não permite acessar práticas culturais em que "chifre" seja "recipiente onde se guarda o rapé”, como fazem Cardoso e Ferreira (2000), em O léxico rural: glossário e comentários, em seus estudos sociodialetais.

Além disso, o lexema "chifrar" adquire, no contexto do semiárido, o sentido de "botar ou por chifre", "botar corno ou por corno", cujo valor acrescentado ao sentido de "chifre" é o de infidelidade conjugal. Assim, homens e mulheres com "chifres" são os "chifrudos", os que recebem "chifres" ou "cornos", que traem seus parceiros.

Para Robert Galisson (1987 p. 55-56), a carga cultural compartilhada (CCP) é o valor acrescido ao sentido denotativo da palavra e que é familiar entre os membros pertencentes a uma determinada cultura.

Carga - traz a ideia de suplemento, acréscimo ao conteúdo da palavra.

Cultura - inscreve esta carga além da denotação de que tratam os dicionários da língua, ou seja, uma dimensão semântica, isto quer dizer, em uma conotação singular, não presa à tarefa da dicionárica clássica, ou seja, a uma dimensão pragmática.

Partilhada - épróprio da cultura (toda cultura é um produto comunitário), mas, em ocorrência, esta partilha é de interesse de um número maior de interlocutores que se alia a esta comunidade.

A carga cultural compartilhada está além da denotação e é resultante do uso que se faz das palavras nas culturas, nas práticas cotidianas. Dessa forma, um mesmo significante pode inscrever diferentes cargas culturais em diferentes contextos culturais. Em outros termos, se a CCP é adquirida na vida, nas práticas ordinárias, em contextos reais de interações, logo povos diferentes tendem a acrescentar valores distintos ao sentido de uma mesma palavra. Os fatores que interferem são vários: são os elementos do contexto temporal, que podem mudar de geração para geração; do contexto espacial porque muda 
de lugar para lugar; e do contexto enunciativo, porque, em determinadas situações de interação, os interlocutores optam por determinados sentidos. Por exemplo, os sentidos atribuídos à palavra "chifrudo", embora partilhado, não é sempre requerido em uma comunidade. Um exemplo significativo da variação da CCC é, no contexto brasileiro, a extinção dos nomes estereotipados por força da criminalização do racismo e da homofobia. As palavras "veado" e "frango", que carregam o preconceito culturalmente partilhado contra homossexuais masculinos no Brasil, estão cada vez mais em desuso no vocabulário de jovens. Na realidade, o que fica em desuso não é o significante, porque ele se estabiliza com o seu significado referencial, mas a carga cultural partilhada como um preconceito tende se perder ao longo do tempo e de geração em geração. Há ainda de se considerar como determinante da natureza dinâmica da lexicultura o processo de letramento ou de literacia escolar. A universalização da escrita pela escola, assim como dos termos que ela elege como sendo escolarmente válidos ou de prestígio, também pode atuar no sentido de ameaçar a carga cultural partilhada em certas palavras.

Como aponta Robert Galisson (2000),

a lexicultura é, às vezes, um processo interrompido e um produto em estado de transformação constante. No tempo e no espaço, ambos ressaltam o transporte pelas palavras dos traços hereditários em perpétuo transformar-se. Este movimento e esta dinâmica não desprezível explicam a complexidade do objeto de estudo, mas também seu misterioso atrativo. Sua notável capacidade de renovar às fontes. (GALISSON, 2000, p. 73)

Em suas considerações prospectivas, portanto, o autor aponta sobre "o transporte no espaço e no tempo, através das palavras, dos traços hereditários das culturas". Nos territórios semiáridos nordestinos, marcadamente multiculturais, lidamos com essas transformações espaciais e temporais dos significados culturais das palavras, que são amplamente férteis para a pesquisa e para a educação intercultural. Uma ilustração dessa transformação pode ser notada nas diferentes cargas culturais implícitas que a palavra "caboclo" inscreve em diferentes espaços e estágios das culturas indígenas e quilombolas no sertão semiárido brasileiro.

\section{Caboclo}

s.m. 1. Mestiço de índio com branco. 2. Sertanejo, caipira. Adj.3. Relativo a ou ao próprio de caboclo; 4 . Indígena; nacional, nativo.

(Minidicionário Luft. São Paulo: Ática, 2000)

\section{Caboclo}

Ca.bo.clo/substantivo. Diz-se do espírito que se manifesta durante práticas religiosas, como a do Samba de Véio. Acredita-se que é o espírito de um índio que vem durante a manifestação não com intuito de assustar ou fazer mal a ninguém, mas com o intuito de ajudar, dar conselhos de sabedoria, curar enfermidades e celebrar a vida. Uso: Desceu o caboclo nele.

(ABC Quilombola. Juazeiro: UNEB, 2014) 
A palavra "caboclo", tal como é definida no Minidicionário Luft, está em desuso nas comunidades indígenas do sertão baiano em função da carga cultural racista que ela agrega e que foi, durante as retomadas dos territórios, muito empregada pelo povo branco, como estratégia de enfraquecer a identidade indígena. Durante uma visita, em meados de 2014, ao território Kiriri, no semiárido baiano, o índio Bernardino, vice-cacique da Aldeia Kiriri Mirandela, confessou-nos, em uma entrevista, que já processou e rompeu com um amigo branco, por tê-lo chamado de "caboclo". A luta pela retomada do território, segundo os índios, é permanente, logo a luta contra a discriminação, da mesma forma, não pode cessar e uma parte dessa luta é a defesa de seus nomes.

A palavra "caboclo", tal como é definida no $A B C$ Quilombola, por outro lado, ainda está em uso em comunidades quilombolas e, além da sua definição universal "mestiço de negro com índios", a ela é somado um significado cultural partilhado entre o povo negro dessas comunidades, "o espírito que se manifesta nas práticas religiosas do candomblé". Além disso, vale notar o processo de certificação das comunidades remanescentes de quilombos no sertão semiárido baiano: cada vez mais novas gerações passam a compartilhar esses sentidos que haviam se estabilizado entre os mais velhos, especialmente os mais próximos das religiões de matriz africana, como o candomblé.

O dinamismo das atividades lexiculturais, ou seja, de inscrição de valores culturais às palavras é um desafio também para o ensino, uma vez que o currículo escolar do ensino do léxico, na vertente língua-cultura, demanda, além do conhecimento cartográfico das palavras de um território, o trabalho formativo com os estudantes no sentido de perceber a carga cultural partilhada nos diferentes espaços, tempos e comunidades étnicas do semiárido, tendo em vista a efetivação de uma comunicação intercultural bem sucedida entre os povos e entre gerações. Como aponta Galisson (2000 p. 73), é a lexicultura de fato um objeto em constantes transformações, entretanto essa dinâmica não desprezível explica não só a complexidade do objeto de estudo mas também o quanto é atraente. Isso faz com que a pesquisa em lexicultura tenha tanto a acrescentar à pesquisa lexicográfica e à educação em língua-cultura em diferentes comunidades sociolinguísticas, como são os territórios de identidade do semiárido nordestino e brasileiro.

\section{METODOLOGIA: DA PESQUISA-FORMAÇÃO EM LEXICOGRAFIA CULTURAL}

Nesta seção, são expostos os procedimentos metodológicos adotados na pesquisa lexicográfica empreendida.

\subsection{A PESQUISA SOBRE O LÉXICO}

A lexicologia é uma disciplina teórica que nos fornece modelos de investigação sobre a estrutura, a diversidade e sobre os significados do léxico em variados contextos de uso (ISQUERDO, 1998). Em outros termos, a lexicologia realiza pesquisas sobre o léxico a partir de abordagem quantitativa, com ênfase nas quantificações de ocorrências e formalização lógico-semânticas do léxico de uma determinada língua, e a partir de uma 
abordagem qualitativa, com ênfase nas relações entre as palavras e as culturas, por meio de cartografias de palavras que podem ser associadas, por interpretação das suas ocorrências em corpus, a um determinado contexto geográfico: "o léxico do semiárido", "o léxico rural", “o léxico acreano" etc. $\mathrm{Na}$ abordagem qualitativa, é fundamental a associação entre o estudo linguístico do léxico e o estudo do contexto sociocultural do qual as palavras são parte. Por exemplo, o estudo da unidade lexical "umbuzada" fora do contexto cultural, histórico, geográfico ou ambiental pode-nos fornecer informações já previstas nos estudos léxico-semânticos, já que, como é conhecida a composição da palavra como uma derivação da palavra "umbu", logo é possível situá-la no campo semântico do alimento ou, para ser mais preciso, de um alimento derivado do fruto "umbu".

O mesmo raciocínio lógico-semântico descrito anteriormente pode ser repetido para o exame de outras palavras compostas, como, por exemplo, "laranjada", "feijoada" etc. No entanto, quando a sua realidade extralinguística e cultural é potencializada, a unidade lexical "umbuzada" precisa necessariamente traduzir em seus significados o contexto geográfico: em quê? para quem? e como? As palavras fazem sentido. Por isso, a definição de palavras e das palavras em verbetes lexicográficos que tem interessado a esta pesquisa precisa necessariamente incluir uma orientação qualitativa, e também pragmática, como parte da investigação lexical e lexicográfica. Nesse caso, portanto, o nosso foco é, além do sentido imediatamente pressuposto nas palavras, a realização de pesquisas nas culturas e, nesse processo, o estudo dos significados em ação, a significação, quando o que está em evidência não é a palavra em si, mas as interações sociais e interculturais mediadas pelo léxico.

A pesquisa sobre o léxico numa abordagem qualitativa e pragmática, sem dúvida, é complexa. Os dados não estão dados ou estabilizados em documentos escritos e, por isso, é preciso gerá-los, a partir de fontes variadas. Nessa busca, podemos incluir os textos escritos, mas também textos de língua falada e, fundamentalmente, as práticas sociais e culturais dos povos. Os dados que interessam ao pesquisador da relação entre o léxico e a cultura não são apenas o léxico, enquanto unidade da língua, nem o campo e o subcampo, enquanto conjunto de palavras ou rede de sentido de uma área. Muitos estudos partem da linguística histórica e investigam o léxico e a cultura de determinadas épocas cujo foco privilegiado é o campo semântico dos léxicos textualizados nos documentos históricos (cf. QUEIROZ, 2014).

No nosso caso, o campo semântico é um conceito útil, por exemplo, para o agrupamento das palavras que compõem a rede de signos e significados da cultura do vaqueiro, porém os sentidos que compõem o universo lexical do vaqueiro são redimensionados a partir da significação, ou seja, dos significados que emergem da ação e de interlocuções no curso da vida, nas culturas. Assim, a partir de pressupostos da pragmática, entendemos que o dinamismo dos usos lexicais assume igual importância na lexicografia e na definição da metodologia qualitativa para a pesquisa sobre o léxico e as culturas. Mostramos isso, por exemplo, na complexidade das definições da palavra "bocapiu" e "aió", em que a investigação necessariamente requer o apoio em uma abordagem qualitativa, ou seja, na interpretação e dimensão pragmática ou discursiva dos dados. Sem esse viés etnográfico, a investigação sobre a relação palavras e culturas perde 
os sujeitos. Nesse caso, por isso, o nosso objeto de pesquisa não se define como uma pesquisa sobre o léxico ou sobre uma lista de palavras de campos e subcampos lexicais, mas, sobretudo, como uma pesquisa com o léxico que inscreve uma realidade cultural implícita, além da sua definição semântica e universal, assim uma pesquisa lexicultural.

\subsection{A PESQUISA COM O LÉXICO DAS CULTURAS}

O objeto de estudo desta proposta de investigação são as palavras das culturas, com base na lexicografia social e cultural. De alguma forma, a pragmática visa acessar, revelar e interpretar as palavras que têm relevância para o cotidiano no presente, no passado e no futuro dos povos. Particularmente, as palavras a que buscamos acessar são as que estão em uso em diferentes práticas culturais e em atividades de ensino-aprendizagem, incluindo a formação de educadores em contextos de educação intercultural. Em outros termos, o que pretendemos realizar são pesquisas com a lexicultura, com atenção ao significado acrescido às palavras pelo uso que se faz delas em experiências culturais específicas. A entrada da lexicultura em programas de ensino-aprendizagem no semiárido brasileiro, sem dúvida, é uma alternativa de acesso por estudantes estrangeiros e estudantes brasileiros de outros territórios às informações pressupostas nas palavras, ou seja, aquilo que não interessa heuristicamente à lexicografia universal e à cultura dicionarística tradicional.

Como aponta Pruvost (2004),

as definições dos dicionários de língua são precisas, mas elas ficam desencarnadas relativamente às conotações que todo falante nativo tem conhecimento desde os primeiros contatos com a língua. Com efeito, há outra definição qualificada como lexicultural, prenhe e pragmática, instalada no espírito de cada nativo. Essa definição, própria de cada país e de sua experiência, emerge como complemento às definições fornecidas nos dicionários, cuja tradição determina que estes últimos se limitem à denotação, suposta objetiva. (PRUVOST, 2004, s. p.)

O "chapéu de couro" do vaqueiro pertence ao conjunto de palavras e à rede de significados do campo semântico das vestimentas e do subcampo semântico dos chapéus, porém, em sua dimensão pragmática, nos interessa o fato de ser um tipo de chapéu central na definição da cultura do vaqueiro e, como tal, contém pressupostos culturais implícitos da arte do couro compartilhados e amplamente conhecidos nas comunidades catingueiras do sertão semiárido nordestino - sem contar, obviamente, com as imensas variações do significante e das motivações icônicas que essas variações podem ter em função dos usos que se fazem nas comunidades específicas. Nas cidades em que as atividades do vaqueiro estão extintas, as vestimentas são utilizadas em outras práticas, como, por exemplo, nas missas.

Assim, passada a etapa de problematização do conceito de campo e subcampos semânticos, tornou-se amplamente interessante trazer para o projeto o conceito de comunidade linguística. Mas é importante não perder de vista que, assim como o conceito de cultura é pouco explorado pela maioria dos linguistas que pesquisa a relação língua e cultura, o problema central que traz a noção de comunidade linguística é que, em geral, 
os linguistas sempre exaltam a língua e apenas tangenciam a comunidade ou o social. Para Louis-Jean Calvet (2002),

a única maneira de ir até o fim da concepção da língua como fato social não é perguntar quais os efeitos da sociedade sobre a língua, pois isso seria, uma vez mais, fazer o problema sociolinguístico derivar do problema linguístico, como um problema diferente, sucessivo ou ulterior. Trata-se, bem ao contrário, de dizer que o objeto de estudo da linguística não é apenas a língua ou as línguas, mas a comunidade social em seu aspecto linguístico. (CALVET, 2002, p. 120-121)

No nosso entendimento, a noção de comunidade linguística, tal como é expandida por Calvet (2002), pode ser equivalente para efeitos metodológicos a locais ou comunidades lexiculturais, tal como é afixada na pragmática lexicultural. Essa equivalência se deve ao fato de o objeto da pesquisa, além das palavras, ser aquilo que elas fazem, lembram ou fazem ressurgir do universo extralinguístico, ou seja, as informações implícitas, subentendidas nas e pelas palavras ditas de cultura. Como sinaliza Certeau (1987), o que nos interessa não é o sentido literal que as palavras denotam em dicionários, mas, sobretudo, os sentidos que estão além delas, os valores acrescentados, a partir do concreto, do uso que se faz dos léxicos nas práticas culturais singulares cotidianas.

Portanto esse deslocamento de estudo sobre o léxico, inicialmente orientado por uma abordagem sócio-histórica, e a certeza de que os estudos lexicográficos do semiárido nada acrescentariam ao que já havia sendo feito na sociolinguística e na dialetologia nos levam a buscar esses deslocamentos, ou seja, nos motivam a ampliar as pesquisas sobre o léxico e a lexicografia, que chamamos de lexicografia intercultural do semiárido, para os procedimentos da pesquisa sobre as definições lexiculturais, tendo em vista as informações pragmáticas comportadas ou fixadas nas palavras pesquisadas nos projetos e subprojetos da pesquisa e a edição de verbetes culturalmente relevantes, por exemplo por intermédio das oficinas de lexicografia cultural com professores que realizamos na Universidade do Estado da Bahia (UNEB, Brasil).

\subsection{PESQUISA-FORMAÇÃO}

No Brasil e no mundo, muitos investigadores de diferentes áreas do conhecimento, em especial, da Educação e da Linguística Aplicada, têm apontado a formação de professores como um objeto de interesse para a produção de resultados e políticas para a melhoria do ensino-aprendizagem. Há muitos desdobramentos metodológicos para esse fim, no entanto estão longe de efetuar um estado da arte das pesquisas sobre a formação do professor. $\mathrm{Na}$ definição metodológica deste trabalho, é necessário situar a pesquisaformação como a que aponta modos de intervenção no local de trabalho do professor, em que o pesquisador e o professor se formam em comunhão, em que a teoria e a prática não se rompem, mas se complementam para construir de cada lado a melhor maneira de melhorar a formação e a prática de ensino nas escolas.

A pesquisa sobre lexicografia cultural na formação docente foi realizada no contexto do semiárido baiano, brasileiro, e adota o pressuposto da lexicografia como um 
modo de registro pela língua, de acesso e de revelamento das culturas pela palavra e pelo uso que se faz dela em diferentes sítios culturais. Os dados envolvem, além da seleção de diferentes documentos, contendo palavras em uso, as atividades de mobilização de oficinas lexicográficas com educadores de escolas e etnias diversas do semiárido baiano. $\mathrm{Na}$ prática de coleta lexical, as observações do terreno foram fundamentais. Além dessa técnica, que envolveu documentos de língua falada e escrita, utilizamos uma ficha de lexicografia, conforme figura abaixo, como instrumento de levantamento de registro das palavras ditas culturais. Assim, quando escolhemos uma comunidade lexicultural, por exemplo a cultura do vaqueiro, a entrada dos pesquisadores na cultura é acompanhada de uma ficha com a seguinte configuração:

Quadro 1: Ficha de Registros Lexicográficos

\begin{tabular}{|c|c|c|c|c|}
\hline $\begin{array}{c}\text { Contexto } \\
\text { cultural }\end{array}$ & Corpus & Palavras & $\begin{array}{l}\text { ções } \\
\text { cas }\end{array}$ & $\begin{array}{l}\text { Informações } \\
\text { pragmáticas } \\
\text { e culturais }\end{array}$ \\
\hline $\begin{array}{l}\text { Contextos de } \\
\text { cultura em que } \\
\text { serão } \\
\text { explorados do } \\
\text { ponto de vista } \\
\text { lexicultural: } \\
\text { territórios } \\
\text { indígenas, } \\
\text { quilombolas, } \\
\text { vaqueiro, } \\
\text { catingueiros, } \\
\text { pescadores } \\
\text { etc. }\end{array}$ & $\begin{array}{l}\text { Materiais } \\
\text { linguísticos } \\
\text { dos quais } \\
\text { serão extraídas } \\
\text { as palavras: } \\
\text { narrativas e } \\
\text { entrevistas } \\
\text { orais, obras } \\
\text { literárias, } \\
\text { cartas } \\
\text { pessoais, } \\
\text { documentários } \\
\text { etc. }\end{array}$ & $\begin{array}{l}\text { Itens lexicais } \\
\text { em uso nos } \\
\text { materiais } \\
\text { linguísticos. } \\
\text { Aqui procede a } \\
\text { recolha de } \\
\text { palavras } \\
\text { nomeadamente } \\
\text { da cultura, ou } \\
\text { seja, palavras } \\
\text { culturalmente } \\
\text { relevantes na } \\
\text { comunicação } \\
\text { intercultural. }\end{array}$ & $\begin{array}{l}\text { O sentido } \\
\text { referencial, } \\
\text { denotativo, } \\
\text { universalizado } \\
\text { e encontrado } \\
\text { em dicionários } \\
\text { da língua, em } \\
\text { geral, nos } \\
\text { dicionários } \\
\text { escolares ou } \\
\text { aprovados pelo } \\
\text { ministério da } \\
\text { educação do } \\
\text { país. }\end{array}$ & $\begin{array}{l}\text { Os } \\
\text { significados } \\
\text { locais e, às } \\
\text { vezes, } \\
\text { implícitos, } \\
\text { acrescidos ao } \\
\text { sentido } \\
\text { referencial e } \\
\text { partilhados em } \\
\text { usos nos } \\
\text { variados } \\
\text { contextos } \\
\text { culturais. }\end{array}$ \\
\hline
\end{tabular}

As pesquisas realizadas através dessa ficha permitem mostrar várias dimensões das palavras para o pesquisador e, além disso, fazem com que os estudantes e professores envolvidos no trabalho de campo aprendam a entrar na cultura com as palavras e, ao mesmo tempo, a voltar para as palavras, após a imersão na realidade, em entrevistas, visitas de campo etc. A edição de pequenos glossários envolvendo os povos dos sítios pesquisados constitui a última etapa do trabalho e tem a ver com a técnica da pesquisaformação ou pesquisa-ação-formação (MARIANO, 2013). O objetivo da pesquisaformação é, portanto, fazer com que os povos que vivem ou atuam nos territórios culturais, além de nos fornecer informações do contexto, possam conhecer os procedimentos e desdobramentos de uma pesquisa lexicultural em sua comunidade. Assim, um educador ou um estudante residente nessas comunidades tornam-se também atores da pesquisa e não apenas fornecedores de palavras e dos seus sentidos, enquanto objetos de investigação. Esse desenho de pesquisa está sendo motivado também pela 
necessidade que tem a linguística aplicada de cunho antropológico de aprimorar os desdobramentos éticos nas pesquisas com a língua em uso, tal como estamos experimentando em lexicografia intercultural e em lexiculturalidade.

\section{RESULTADOS: DA PRODUÇÃO DE DICIONÁRIOS DAS CULTURAS}

Os professores, sujeitos das culturas e participantes dos projetos de lexicografia no âmbito da licenciatura intercultural, foram encorajados, durante várias oficinas, para a realização de pesquisas com o léxico relevante e em uso em suas aldeias, povoados e nas pequenas cidades do semiárido. Como resultados dessa atividade, foram elaborados os seguintes "dicionários", sob a forma de produtos experimentais de lexicografia intercultural: o Dicionário regional do Uauá, o $A B C$ do vaqueiro e o $A B C$ do artesanato Kiriri.

\subsection{O DICIONÁRIO REGIONAL DO UAUÁ}

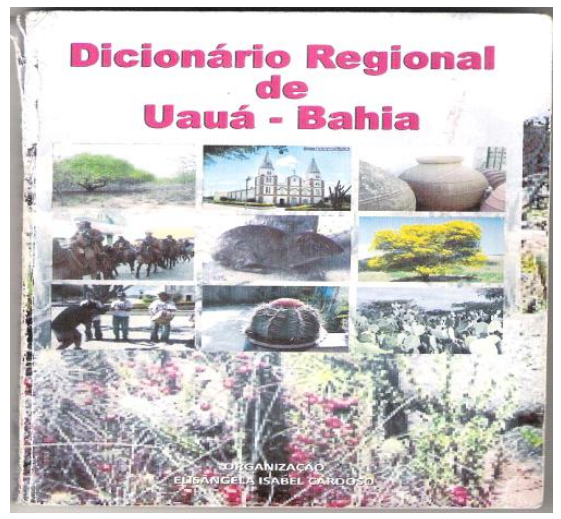

Elizângela Cardoso realizou, com um grupo de estudantes do Ensino Médio, um exaustivo levantamento de palavras em uso na região de Canudos, mais especificamente no município de Uauá, no sertão baiano. Em seu estudo, o grupo coletou aproximadamente 500 palavras nas zonas rural e urbana das referidas localidades. As palavras que julgávamos ser de uso regional foram transformadas em verbetes nas oficinas de edição lexicográfica, como, por exemplo, o lexema "bacuri", a seguir.

\section{BACURI}

ba.cu.ri/substantivo. 1. Porco pequeno, filhote do porco. 2. Criança, menino. Usos: 1. Os bacuris de Afonso são castrados. 2. Ainda é um bacuri, mas já fala que nem homem feito.

O trabalho do grupo pressupunha a visão sociocultural do léxico, por isso a estruturação dos verbetes contém as seguintes informações do léxico: entrada, categoria gramatical, fonte, área, definição e contexto (DIONÍSIO, 2007).

No processo, Elisângela Cardoso envolveu estudantes e professores de Língua Portuguesa da cidade para, entre outras atividades, entrevistar moradores antigos das áreas 
das comunidades, transcrever os itens lexicais mais estáveis nas narrativas populares e, por fim, editar verbetes que, em conjunto, foram transformados no Dicionário regional do Uauá. Um conflito marcante na edição dos verbetes foi o estudo da lexia "umbuzeiro". Uma parte desse estudo mostra que o léxico "umbu" é dicionarizado, porém a lexia "umbuzada” não está dicionarizada em dicionários escolares, por exemplo.

A ausência de certas palavras marcadamente das culturas do semiárido, como é o caso do substantivo "umbuzada", foi o resultado empírico motivador para a elaboração da proposta de pesquisa sobre o léxico do semiárido, iniciada em 2012, cujo objetivo central era tornar visível, por outros dicionários, as palavras do sertão semiárido. A dificuldade da cultura letrada e dos dicionários universais em nomear e definir as palavras esbarra nas dificuldades que essa cultura tem de adentrar nos campos, de conviver com outras culturas não urbanas e, portanto, de perceber as paisagens rurais da caatinga brasileira e nordestina de outro modo senão pela grande mídia.

\subsection{O ABC DO VAQUEIRO}

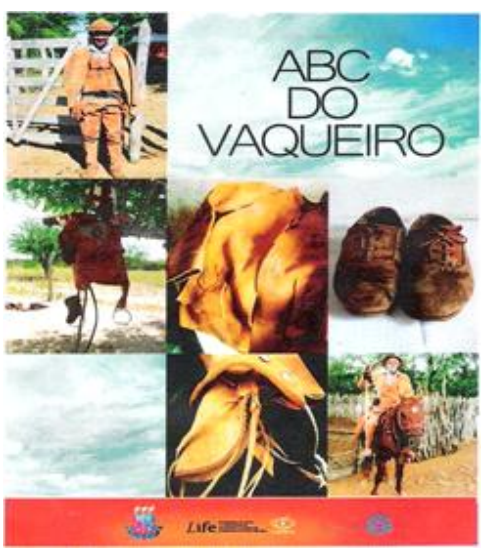

O glossário intitulado $A B C$ do vaqueiro foi a segunda experiência de pesquisa em lexicografia e léxico da cultura, com ênfase na formação de educadores. Nesse caso, a pesquisa envolveu professores de escolas rurais e da Educação Básica nas atividades de campo, a partir da imersão no seu passado para resgatar palavras e experiências relevantes na tradição, como, por exemplo, ocorreu com a formação do verbete "ajuntamento". O levantamento foi feito a partir de visitas a vaqueiros antigos e com a realização de entrevistas para a formação de corpus, o levantamento de documentos escritos e audiovisuais e a pesquisa em museus.

O dicionário foi editado, inicialmente, a partir do fichamento lexicográfico de palavras e dos significados mais antigos e mais atuais nas práticas dos vaqueiros. Foram considerados, por exemplo, o vestuário: gibão, chapéu-de-couro, roló, perneira e os instrumentos: alforje, bocapiu, berrante, bride, sela, cambão etc. As definições foram editadas sempre considerando, por extensão, a dimensão pragmática do verbete, tendo em vista que algumas palavras, a priori, não pertencem ao acervo lexicultural do vaqueiro, porém são apropriadas como tal, a partir de práticas culturais reais de cada contexto geográfico, 
ou seja, os vaqueiros de certo território dão sentido diferente para alguns instrumentos e, logo, as definições do tipo função tendem a ser diferentes. Isso fica mais evidente na definição de "berrante", que, na atividade de campo, tem a função de guiar ou localizar a boiada, mas nas reuniões ou festas de vaqueiro tem função meramente alegórica.

O conhecimento da dimensão pragmática das definições lexicográficas foi uma oportunidade de conhecimento muito produtiva para os educadores em geral. Os alfabetizadores em atuação nas regiões pesquisadas passaram a conhecer melhor a sua realidade, conquistaram a autoestima de pesquisadores do seu meio e passaram a experimentar um modo de acesso à cultura através das palavras; finalmente, experimentaram a produção de material didático para uso em sala de aula e para atender a uma demanda urgente, que é a aproximação da escola com a língua, com a cultura e com a sociedade de modo mais profundo e enriquecedor.

\subsection{O ABC DO ARTESANATO KIRIRI}

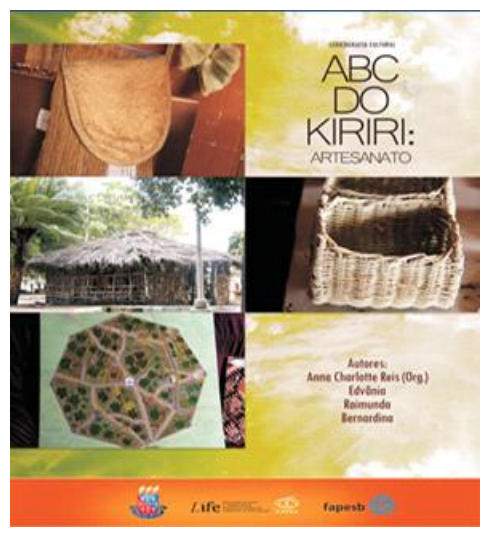

O glossário intitulado $A B C$ do artesanato Kiriri foi a terceira experiência de pesquisa em lexicografia envolvendo a formação de educadores. A pesquisa contou com a participação de Anna Charlotte Reis, bolsista de iniciação científica, e com um grupo de educadores da etnia Kiriri, em formação pela Licenciatura Intercultural de Educação Escolar Indígena (LICEEI/UNEB). As professoras Edvânia Kiriri e América Kiriri participaram do projeto como colaboradoras, orientando a formação de um corpus de entrevistas com as lideranças indígenas e com demais educadores das aldeias de Marcação e Mirandela, situadas ao Norte da Bahia - Brasil.

A comunidade indígena Kiriri está localizada no Norte da Bahia e foi escolhida para realizar esse trabalho devido à necessidade de se registrar o maior número de palavras possíveis, palavras essas que vêm se perdendo ao longo do tempo, devido à falta de registros escritos. O campo semântico escolhido para a realização do levantamento e da edição do dicionário foi o artesanato Kiriri, por se tratar de um traço muito importante da identidade cultural desse povo.

A produção do dicionário de bolso, $A B C$ do artesanato Kiriri, tal como as experiências anteriores, trouxe para a lexicografia, como descreve Anna Charlotte Reis (2014), os 
nomes de objetos tão comuns em práticas culturais indígenas, como é o caso de "abano", "aió" e "prochô".

Quem já viu um abano sabe que ele serve para abanar o fogo, muito usado em lugares onde ainda existem fogões de lenha, por exemplo. E o aió, que é uma bolsa feita de fibra crauá ou imbé? Já prochô, na língua Kiriri, é uma simples pulseira, daquelas que se usa para enfeitar o braço, sim para enfeitar o braço apenas, aquele adereço que as mulheres gostam e alguns homens também. (REIS, 2014, p. 7)

A demanda de realização de uma lexicografia da cultura indígena com a participação dos educadores é muito visível. O dicionário do artesanato Kiriri é uma pequena contribuição para tornar conhecida uma parte relevante do universo lexical e os sentidos das palavras que, apesar da grande importância para a vida desse povo, ainda estão ausentes nos dicionários gerais da língua portuguesa brasileira. Nas poucas situações, quando aparecem, em diversos casos, trazem definições vagas, superficiais e estereotipadas. Por isso, o estudo do léxico Kiriri e a formatação desse dicionário é uma experiência que atende a uma demanda de visibilidade lexicográfica muito requerida pela cultura indígena do Nordeste brasileiro.

\section{CONSIDERAÇÕES FINAIS}

O trabalho, portanto, apresenta duas linhas de resultados, a saber: uma demanda forte da lexicografia cultural como uma linha de estudos no campo aplicado dos estudos lexicais; e, ainda, os desdobramentos de pesquisa-formação ou de uma pesquisa-ação orientada para a formação continuada de educadores em seu local de trabalho. O centro do estudo é, sem dúvida, a oficina de lexicografia cultural, cuja ênfase é a edição lexicográfica de palavras culturalmente relevantes nas comunidades rurais e urbanas do sertão semiárido baiano, incluindo a cultura catingueira. No entanto há uma tradição de pesquisas com os educadores e sobre as práticas docentes no âmbito da linguística aplicada brasileira que não pode ficar à margem da intervenção educacional ou linguística nas comunidades, porque há processo de exclusão dos sujeitos educacionais que atuam nesses contextos e, portanto, estamos sinalizando que há uma emergência de instrumentalização letrada de educadores para o fazer científico que possa, minimamente, inovar e descobrir novos conhecimentos na escola.

As oficinas de lexicografia foram, sem dúvida, esse instrumento de aproximação da pesquisa com a escola. Durante a realização de oficinas, constatamos as dificuldades dos educadores de trazer a dimensão pragmática das palavras para a edição de verbetes lexicográficos, por isso a proposta de trabalho é motivada por essa necessidade de conhecer os fundamentos da lexicografia (PONTES, 2001) e da lexicografia sociocultural (ISQUERDO, 1998). Em fichas de levantamento de registros lexicográficos, foram levantadas as palavras em corpus de língua falada, textos literários e documentários e, no final de cada oficina, os professores em formação editaram os seguintes dicionários: o Dicionário regional do Uauá, organizado por uma educadora, em parceria com estudantes de Ensino Médio; o $A B C$ do vaqueiro, organizado por um grupo de educadores da Plataforma 
Freire; e o $A B C$ do artesanato Kiriri, por um grupo de Educadores da Licenciatura Intercultural de Educação Escolar Indígena.

Os resultados apontam desafios éticos da pesquisa com a língua nas comunidades, sendo a lexicografia cultural um valioso instrumento de coleta lexical, respeitando as interfaces e a carta cultural inscrita nas palavras em uso nas comunidades. Um pesquisador, por mais bem intencionado que possa ser e por mais bem amparado teoricamente que possa estar, é sempre desprovido da autoridade suficiente para se apropriar de significados tão bem sedimentados na tradição das famílias e dos grupos étnicos do semiárido. Nesse sentido, a pesquisa em formação e uma pesquisa para a formação é o mínimo que podemos fazer para instrumentalizar e potencializar a população, em especial os educadores, para formatar parcerias entre Universidade e comunidade, entre teoria e prática, e apontar algum horizonte de que a pesquisa e a presença da ciência nos territórios permitem um fortalecimento tal que a nossa tradição científica, exageradamente grafocêntrica, não alcançaria, ao menos não tão imediatamente.

\section{REFERÊNCIAS}

ALMEIDA, Norma L.; CARNEIRO, Zenaide. Amostras da língua falada no semiárido baiano. Feira de Santana: UEFS, 2009.

AUROUX, Silvan. A revolução tecnológica da gramatização. Campinas: Editora da Unicamp, 1992.

ARAGÃO, Maria do Socorro. A linguagem regional-popular no Nordeste do Brasil: aspectos léxicos. IX Simpósio Internacional de Comunicación Social, Santiago de Cuba. Actas I. Santiago de Cuba - Cuba: Centro de Linguística Aplicada - Santiago de Cuba, 2005, v. I, p. 457-459. Disponível em: http://www.profala.ufc.br/Trabalho2.pdf. Acesso em 01.12.2011.

ARAGÃO, Maria do Socorro. Falares nordestinos: aspectos socioculturais. Anais do VII Congresso Internacional da Abralin, Curitiba, 2011.

BAGNO, Marcos. Português ou brasileiro? Um convite à pesquisa. São Paulo: Parábola Editorial, 2001.

BARBOSA, Lúcia Maria de Assunção. O conceito de lexicultura e suas implicações para o ensino-aprendizagem de língua portuguesa. Filologia e Linguística Portuguesa, n. 10-11, p. 31-41, 2008/2009.

BASÍLIO, Margarida Maria de Paula. Estruturas lexicais do português: uma abordagem gerativa. Petrópolis: Vozes, $1980 . \quad$ Disponível em: http://www.filologia.org.br/vcnlf/anais $\% 20 \mathrm{v} / \mathrm{civ} 6$ 18.htm. Acesso em: 16 dez. 2011.

BIDERMAN, Maria Tereza C. Os dicionários na contemporaneidade: arquiteturas, métodos e técnicas. In: OLIVEIRA, Ana M. Pinto Pires de; ISQUERDO, Aparecida Negri. As ciências do léxico. $2^{\mathrm{a}}$ ed. Campo Grande: Editora UFMS, 2001, p. 131-144. Disponível em: http://acd.ufrj.br/ pead/tema05/formacaolexico.html. Acesso em: 10 dez. 2011.

BIDERMAN, Maria Tereza C. O dicionário como norma na sociedade. Lexicologia, lexicografia e terminologia: questões conexas. Anais do 1 Encontro Nacional do GT de 
Lexicografia e Terminologia da ANPOLL. 22-24 de abril de 1995, UFRJ - Rio de Janeiro. Cursos de Pós-graduação em Letras Vernáculas da Faculdade de Letras UFRJ e em Letras e Linguística da faculdade de Letras UFPE: CNPq, 1998b, p. 161-180. Disponível em: http://acd.ufrj.br/ pead/tema05/formacaolexico. .html. Acesso em: 10 dez. 2011.

BIDERMAN, Maria Tereza C. A formação e a consolidação da norma lexical e lexicográfica no português do Brasil. In: NUNES, José Horta Nunes; PETTER, Margarida (Orgs.). História do saber lexical e constituição de um léxico brasileiro. São Paulo: Humanitas - FFLCH/USP: Pontes, 2002.

CARDOSO, Elisângela. A sociolinguística sertaneja: uma experiência lexicográfica em escola pública de Uauá-Ba. Juazeiro: UNEB-DCH, 2012.

CALVET, Louis-Jean. Sociolinguística: uma introdução crítica. São Paulo: Parábola Editorial, 2002.

CERTEAU, Michel. A invenção do cotidiano: artes de fazer. São Paulo: Vozes, 1995. DIONÍSIO, Ângela Paiva. Gêneros textuais e ensino. $5^{\mathrm{a}}$ ed. Rio de Janeiro: Lucerna, 2007. GALISSON, Robert. Cultures et lexicultures. Pour une approche dictionnairique de la culture partagée. Cabiers de Linguistique Hispanique, v. 7, p. 325-341, 1988.

GALISSON, Robert. La pragmatique lexiculturelle pour accéder autrement, a une autre culture, par un autre lexique. Mélanges, n. 25 (Une didactique des langues pour demain / en hommage au Professeur Henri Holec), 2000.

GONÇALVES, Solange A. Por um planejamento linguístico local. Revista Investigações, v. 22, n. 2, jul./2009.

IRIARTE SANROMAN, Álvaro. A unidade lexicográfica. Palavras, colocações, frasemas, pragmatemas. Braga: Centro de Estudos Humanísticos da Universidade do Minho, 2001. ISQUERDO, Aparecida N. Vocabulário regional da Amazônia acreana. Alfa, São Paulo, p. 93-107, 1998.

ISQUERDO, Aparecida Negri. A propósito de dicionários de regionalismo do português do Brasil. In: ALVES, I. N.; ISQUERDO, A. N. (Orgs.). As ciências do léxico. Campo Grande: UFMS, 2007. Disponível em: http://www.mel.ileel.ufu.br/gtlex /viiengtlex Lpdf/. Acesso em: 16 dez. 2011.

ISQUERDO, Aparecida Negri. Léxico em tempo e espaço: a questão dos regionalismos. In: MARIN, Jérri R.; VASCONCELOS, Cláudio A. (Orgs). História, região e identidades. Campo Grande: UFMS, 2003. Disponível em: http://www.mel.ileel.ufu.br/gtlex Lviiengtlex /pdf/. Acesso em: 16 dez. 2011.

MARCUSHI, Luiz A. O léxico: lista, rede ou cognição social. In: NEGRI, Lígia; FOLTRAN, Maria José; OLIVEIRA, Roberta (Orgs.). Sentido e significação: em torno da obra de Rodolfo Ilari. São Paulo: Contexto, 2004.

MELIA, Bartolomeu. Bilinguismo e escrita. In: D’ANGELIS, W.; VEIGA, J. (Orgs.). Leitura e escrita em escolas indígenas. Campinas: Mercado de Letras, 1997.

NUNES, J. Horta; PETTER, Margarida. História do saber lexical e constituição de um léxico brasileiro. São Paulo: Humanitas - FFLCH/USP; Pontes, 2002.

PRETI. Dino. Sociolinguística - os niveis da fala. São Paulo: EDUSP, 2003.

PRUVOST, Jean. Quelques concepts lexicographiques issus d'une formation française de lexicologie. 2004. Disponível em: http://kdictionaries.com/index.html\#newsletter. 


\section{Revista

SANTOS, Boaventura S. Para um novo senso comum: a ciência, o direito e política na transição paradigmática. $4^{a}$ ed. São Paulo: Cortez, 2002.

SANTOS, Cosme B. Letramento e comunicação intercultural. In: MENDES, Edleise; CASTRO, Maria Lúcia (Orgs.). Saberes em português. Campinas: Pontes, 2008.

SILVA E SILVA, Marlène. La lexiculturologie... en didactologie des langues-cultures. Synergies, n. 1, Portugal, p. 69-89, 2013.

SILVA E SILVA, Marlène F. La pragmatique lexiculturelle en éducation aux langues-cultures: étude d'un cas dans le contexte scolaire portugais. Thèse de doctorat. Braga: Université du Minho, 2006.

TARALLO, Fernando. A pesquisa sociolinguística. $4^{a}$ ed. São Paulo: Ática, 1994.

XATARA, Claudia; BEVILACQUA, Clecir; HUMBLÉ, Philippe R. Marie (Orgs.). Dicionários na teoria e na prática. Como e para quem são feitos. São Paulo: Parábola, 2011.

Recebido em: 28/02/2019

Aprovado em: 07/06/2019

Publicado em: 28/09/2019 